\title{
Airflow Limitation Is Accompanied by Diaphragm Dysfunction
}

\author{
L. HELLEBRANDOVÁ ${ }^{1}$, J. CHLUMSKÝ ${ }^{2}$, P. VOSTATEK ${ }^{3}$, D. NOVÁK ${ }^{3}$, \\ Z. RÝZNAROVÁ ${ }^{4}$, V. BUNC ${ }^{1}$
}

${ }^{1}$ Faculty of Physical Education and Sports, Charles University, Prague, Czech Republic,

${ }^{2}$ Department of Pulmonary Diseases, Thomayer Hospital, Prague, Czech Republic, ${ }^{3}$ Department of Cybernetics, Czech Technical University, Prague, Czech Republic, ${ }^{4}$ Department of Radiology, Thomayer Hospital, Prague, Czech Republic

Received May 1, 2015

Accepted December 18, 2015

On-line April 12, 2016

\section{Summary}

Chronic airflow limitation, caused by chronic obstructive pulmonary disease (COPD) or by asthma, is believed to change the shape and the position of the diaphragm due to an increase in lung volume. We have made a comparison of magnetic resonance imaging (MRI) of diaphragm in supine position with pulmonary functions, respiratory muscle function and exercise tolerance. We have studied the differences between patients with COPD, patients with asthma, and healthy subjects. Most interestingly we found the lung hyperinflation leads to the changes in diaphragmatic excursions during the breathing cycle, seen in the differences between the maximal expiratory diaphragm position (DPex) in patients with COPD and control group $(p=0.0016)$. The magnitude of the diaphragmatic dysfunction was significantly related to the airflow limitation expressed by the ratio of forced expiratory volume in $1 \mathrm{~s}$ to slow vital capacity $\left(\mathrm{FEV}_{1} / \mathrm{SVC}\right),(\%, \mathrm{p}=0.0007)$; to the lung hyperinflation expressed as the ratio of the residual volume to total lung capacity (RV/TLC), $(\%, p=0.0018)$ and the extent of tidal volume constrain expressed as maximal tidal volume $\left(\mathrm{V}_{\mathrm{Tmax}}\right)$, ( $[1], p=0.0002)$; and the ratio of tidal volume to slow vital capacity $\left(\mathrm{V}_{\mathrm{T}} / \mathrm{SVC}\right), \quad(p=0.0038)$ during submaximal exercise. These results suggest that diaphragmatic movement fails to contribute sufficiently to the change in lung volume in emphysema. Tests of respiratory muscle function were related to the position of the diaphragm in deep expiration, e.g. neuromuscular coupling $\left(P_{0.1} / V_{T}\right)(p=0.0232)$. The results have shown that the lung volumes determine the position of the diaphragm and function of the respiratory muscles. Chronic airflow limitation seems to change the position of the diaphragm, which thereafter influences inspiratory muscle function and
\end{abstract}

exercise tolerance. There is an apparent relationship between the position of the diaphragm and the pulmonary functions and exercise tolerance.

\section{Key words}

COPD • Asthma bronchiale • Diaphragm • MRI • Pulmonary function

\section{Corresponding author}

L. Hellebrandová, Faculty of Physical Education and Sports, Charles University, José Martího 31, 16252 Prague 6, Czech Republic. E-mail: hellebrandova@hometherapy.cz

\section{Introduction}

Chronic obstructive pulmonary disease (COPD) and bronchial asthma are obstructive airway diseases that are characterized by airway obstruction, which is progressive and largely irreversible in COPD, and is variable and reversible in asthma (Barnes 2008, Nakawah et al. 2013).

COPD cause an increase in airflow resistance and pulmonary compliance. The expiratory flow limitation prolongs expiration, and this may also lead to pulmonary hyperinflation (Dal Vecchio et al. 1990). COPD is typically associated with weakness of the inspiratory muscles, mainly due to the changed lengthstrength relationship and their remodeling. The decreased inspiratory muscle strength contributes to sensations of dyspnea, and places individuals at risk for respiratory muscle fatigue (Larson et al. 2002). Changes in 
maximum breathing capacity and in maximal exercise tolerance occur in these patients (De Troyer and Wilson 2009).

The purpose of our study is to test whether the diaphragmatic position and shape in supine patients with airflow limitation in deep-breathing maneuvers differ from the diaphragmatic position and shape of healthy persons. We were also interested in finding whether variable and reversible airflow limitation in asthma patients also influences respiratory muscle function. In addition, we investigated whether there is a correlation between pulmonary function, exercise tolerance and the position and shape of the diaphragm.

We assessed the relationship between diaphragm shape and position, exercise tolerance and pulmonary function in the context of the severity of the airflow limitation.

Table 1. Characteristics of the subjects in 3 tested groups.

\begin{tabular}{lccc}
\hline Group & COPD & Asthmatic & Control group \\
\hline Subject, $n$ & 11 & 10 & 10 \\
Male $:$ female & $7: 4$ & $5: 5$ & $5: 5$ \\
BMI, $\mathrm{kg} / \mathrm{m}^{2}$ (range) & $30.04 \pm 9.45(20.4-46)$ & $26.65 \pm 2.89(22.5-28.7)$ & $24.01 \pm 2.73(21.9-29.5)$ \\
Height, $\mathrm{cm}$ (range) & $172.2 \pm 7.07(157-186)$ & $172.8 \pm 9.65(155-182)$ & $174.6 \pm 8.82(160-189)$ \\
Age, years (range) & $59.36 \pm 10.33(30-69)$ & $49.8 \pm 9.81(34-67)$ & $48.8 \pm 11.75(29-67)$ \\
FEV $/$ SVC, \% & $40 \pm 9.27$ & $71.9 \pm 7.45$ & $77.4 \pm 10.59$ \\
TLC\% $\%$ predicted & $125 \pm 11.87$ & $104.9 \pm 13.53$ & $106.8 \pm 7.15$ \\
\hline
\end{tabular}

Values are presented as mean $\pm \mathrm{SD}$, unless otherwise indicated. COPD, chronic obstructive pulmonary disease; BMI, body mass index; $\mathrm{FEV}_{1} / \mathrm{SVC}$, forced expiratory volume in $1 \mathrm{~s}$ to slow vital capacity; TLC, total lung capacity.

\section{Subjects and Methods}

\section{Subjects}

The subjects comprised 31 adults: 10 adults with clinically stable asthma (five males and five females), 11 clinically stable adult patients with mild to severe COPD (seven males and four females), and 10 healthy adult control subjects (five males and five females). The patients with obstructive pulmonary disease were classified by spirometry, according to the degree of airway obstruction. The COPD and asthma subjects exhibited various degrees of airway obstruction, which we classified and then used in order to assess the impact of various degrees of bronchial obstruction on the function of the diaphragm. Asthma patients enrolled in our study had good long-term control of the disease. Stability of disease was defined by stability of the pulmonary function and by low symptom scores and exhaled nitric oxide levels (FeNO). ACT (asthma control test) of the asthma probands was $22.2 \pm 2.04$. The dose of the inhaled steroids was $1280 \pm 900.4 \mu \mathrm{g}$ daily, 9 of 10 asthma probands simultaneously receiving LABA (long acting beta agonists) and 4 of them LTRA (leucotrien receptor antagonists). Duration of disease in asthma probands was $10.5 \pm 6.3$ years. The characteristics of each group are summarized in Table 1.

\section{Methods}

This study was approved by the institutional ethical committee of Charles University, Faculty of Physical Education and Sports. All subjects confirmed that they understood the test procedures and gave their informed consent.

All patients underwent a complex examination of pulmonary function. Spirometric assessments were performed using a calibrated spirometer (ZAN 100 flowhandy II, ZAN, Oberthulba, Germany). Static lung volumes were measured by methane dilution with synchronous measurement of transfer factor for carbon monoxide $\left(\mathrm{TL}_{\mathrm{CO}}\right)$ using the single-breath method (ZAN 300, ZAN, Oberthulba, Germany). The predicted values for the lung function parameters were derived from those published by the European Community for Coal and Steel (Quanjer et al. 1983). Measurements of maximal inspiratory and expiratory pressures at the mouth $\left(\mathrm{PI}_{\max }, \mathrm{PE}_{\max }\right)$, pressure at the mouth $100 \mathrm{~ms}$ after the beginning of a quiet inspiration $\left(\mathrm{P}_{0.1}\right)$ and duty cycle were performed using a commercially available system 
(ZAN 100 flowhandy II with an automatic shutter, ZAN, Oberthulba, Germany) according to the American Thoracic Society/European Respiratory Society standard (American Thoracic Society/European Respiratory Society 2002) and normal values were adopted from the values published by Black and Hyatt (1969). The noninvasive tension-time index for inspiratory muscles $\left(\mathrm{T}_{\text {Tmus }}\right)$ was calculated according to the equation:

$$
\mathrm{T}_{\mathrm{Tmus}}=\mathrm{PI} / \mathrm{PI}_{\max } * \mathrm{TI} / \mathrm{T}_{\text {tot }}
$$

where $\mathrm{PI}=5 \mathrm{P}_{0.1} * \mathrm{TI}$ and $\mathrm{TI} / \mathrm{T}_{\text {tot }}$ is the ratio of mean inspiratory time to total time of respiratory cycle. Neuromuscular coupling was assessed by the ratio of $\mathrm{P}_{0.1} /$ tidal volume $\left(\mathrm{V}_{\mathrm{T}}\right)$. All measurements were performed in triplicate, and were expressed as a percentage of the predicted or absolute values, where the best of at least three reproducible values were used for data processing.

The cardiopulmonary exercise test (CPET) was performed according to the American Thoracic Society (ATS)/American College of Chest Physicians (ACCP) statement on CPET. Each subject underwent a standard incremental exercise test on an electronically braked cycle ergometer (Variobike 500, Ergoline, Niederlauer, Germany). Measurements of oxygen consumption $\left(\mathrm{VO}_{2}\right)$, carbon dioxide output $\left(\mathrm{VCO}_{2}\right)$, tidal volume $\left(\mathrm{V}_{\mathrm{T}}\right)$ and minute ventilation (VE) were assessed by breath-bybreath analysis (Ergostik, Geratherm, Germany). Operational lung volume assessed by the ratio between $\mathrm{V}_{\mathrm{T}}$ and slow vital capacity (SVC) and between $\mathrm{V}_{\mathrm{T}}$ and inspiratory capacity (IC) was used for assessing the mechanical limitation of VE during exercise.

\section{Magnetic resonance imaging Input data}

All patients were scanned using $1.5 \mathrm{~T}$ General Electric Signa HDxt MRI with the 15-M4A software version. The GE FIESTA Cine dynamic sequence was used, configured as follows: $1 \mathrm{NSA}, \mathrm{TR} 3.4 \mathrm{~ms}$, TE $1.3 \mathrm{~ms}$, FA 55, FOV $420 \mathrm{~mm}$. The resulting images were $256 \times 256$ pixels with resolution of $1.64 \mathrm{~mm} /$ pixel. The imaging frequency was $0.5 \mathrm{~Hz}$, and the thickness of each layer was $15 \mathrm{~mm}$. The patients lay in supine position in the apparatus.

The patients were imagined in two different situations: maximal inspiration and maximal expiration. Both situations consisted of 3 images, and during the sequence the diaphragm did not move. The image with the best image quality was manually selected for processing.

\section{Data processing}

The image processing consisted of manual annotation of the diaphragm contour and locating the center of the frontal marker. Typical examples of annotated contours are shown in Figure 1. The center of the marker was located manually by placing a single point (the center of the solid circle in Fig. 1A, and the cross in Fig. 1B) on the image. All assessed parameters were then computed using these annotations.

The assessed parameters were (1) diaphragm height, (2) diaphragm slope, and (3) anteroposterior (AP) size. Parameters (1) and (3) are difference parameters based on a comparison of two situations, and in the subsequent text we therefore refer to "compared situations".

\section{Diaphragm height}

The diaphragm height was measured as the point on the diaphragm contour most distant (perpendicular distance) from a line intersecting the endpoints of a reference diaphragm (Fig. 1). Height of the diaphragm in both maximal expiration (DPex) and inspiration (DPin) was measured. The reference diaphragm for measurement of DPex was the diaphragm in maximal inspiration. DPin was then defined as the height of the diaphragm contour in maximal inspiration itself.

\section{Diaphragm slope}

The diaphragm slope was measured as the angle between a line intersecting the contour endpoints and a horizontal line. The angle has a positive value when the posterior part of the diaphragm is lower than the anterior part (Fig. 1A), and has a negative value otherwise (Fig. 1B,C).

\section{Difference of the anterioposterior diameter}

Changes in anterioposterior (AP) diameter were assessed by measuring the movement of the frontal marker in the horizontal direction, i.e. the horizontal coordinates of the marker in the compared situations were subtracted (see $d_{p}$ in Figs $1 B$ and 1C).

\section{Statistical analysis}

Results are expressed as mean $\pm \mathrm{SD}$. The Kolmogorov-Smirnov test was used to assess the normality of the score distribution. Associations between variables were examined by Spearman's correlation coefficients, and comparisons among the groups were conducted using t-student or Kruskal-Wallis one-way 
analysis of variance by ranks with a post-hoc NemenyiDamico-Wolfe-Dunn test. Statistical significance was assessed using the conventional two-tailed $\mathrm{p}<0.05$ level.
All analyses were performed using GraphPad Prism statistical software, version 4.0.

\section{A}

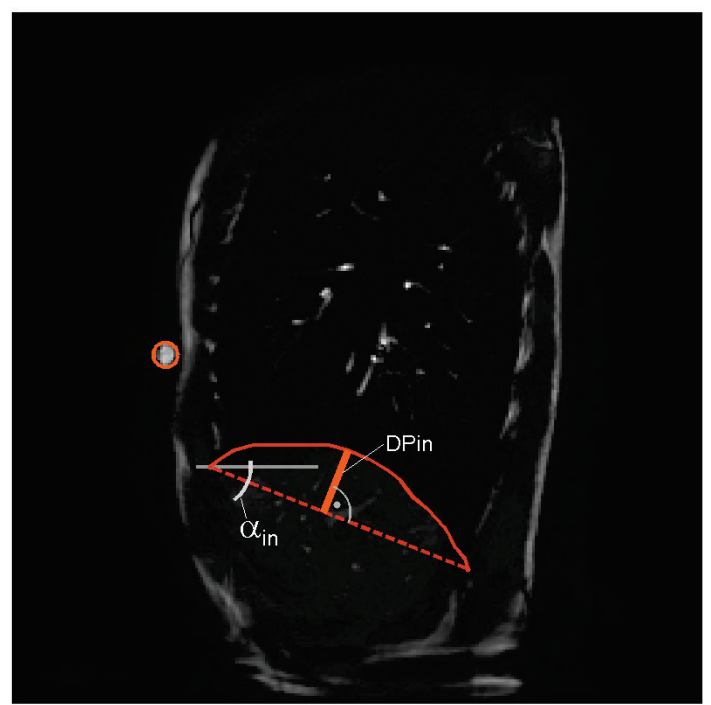

B

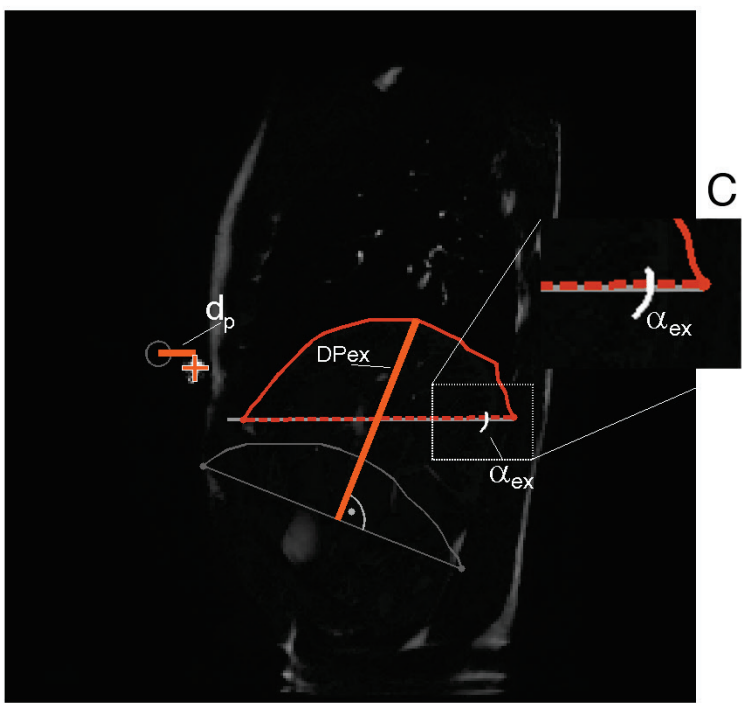

Fig. 1. It illustrates measurement of the diaphragm height (DPin, DPex), declination $\left(a_{i n}, a_{e x}\right)$ and AP size difference $\left(d_{p}\right)$. Diaphragm in maximal inspiration (the reference position) is shown in $\mathbf{A}$ and diaphragm in maximal expiration is shown in $\mathbf{B}$. The height is measured as the maximal distance of the diaphragm contour from the connection of diaphragm's endpoints (dashed orange line); note the maximal inspiration diaphragm serving as a reference for the measurement of DPex in B. The declination is measured as an angle between endpoint connection and a horizontal line; positive angle suggests diaphragm with posterior part lower then anterior (A) and negative value suggests vice versa $(\mathbf{B}, \mathbf{C})$. Inset $\mathbf{C}$ shows part of the subfigure $B$ in detail to better observe the small negative slope $a_{\mathrm{ex}}$. $D_{p}$ is measured as a horizontal distance between the marker in breathe-in (solid circle in A) and breathe-out (cross in B) positions.

Table 2. Cardiopulmonary exercise test results in 3 tested groups.

\begin{tabular}{lcccc}
\hline Parameters & COPD & Asthmatic & Control group & P-value \\
\hline$V_{T} / \mathrm{IC}$ & $71.09 \pm 7.61^{*}$ & $73.9 \pm 7.80$ & $83 \pm 10.41$ & 0.024 \\
$V_{T} / \mathrm{SVC}$ & $0.37 \pm 0.07^{* * *}$ & $0.55 \pm 0.09^{\# \#}$ & $0.63 \pm 0.06$ & $<0.0001$ \\
slope $\mathrm{VE} / \mathrm{VCO}_{2}$ & $31.44 \pm 5.65^{* *}$ & $25.08 \pm 3.68^{\#}$ & $23.5 \pm 2.76$ & 0.002 \\
$\mathrm{O}_{2} \mathrm{pulse} \%$ & $77.64 \pm 30.03^{* *}$ & $93.40 \pm 22.59$ & $117.2 \pm 12.66$ & 0.0052 \\
peak $\mathrm{VO}_{2} \%$ & $63.36 \pm 22.36^{* * *}$ & $92.5 \pm 28.45$ & $117.2 \pm 17.09$ & 0.0005 \\
\hline
\end{tabular}

Values are presented as mean $\pm \mathrm{SD}$, unless otherwise indicated. Comparisons among the groups were conducted using Kruskal-Wallis one-way analysis of variance by ranks with a post-hoc Nemenyi-Damico-Wolfe-Dunn test. $*, * *, * * *$ comparison between COPD and control group $(p<0.01, p<0.005 ; p<0.001) ;{ }^{\#}, " \#$ comparison between COPD and asthmatic $(p<0.01, p<0.005)$. CPET, cardiopulmonary exercise test; COPD, chronic obstructive pulmonary disease; $\mathrm{V}_{\mathrm{T}} / \mathrm{IC}$, ratio of tidal volume and inspiratory capacity; $\mathrm{V}_{\mathrm{T}} / \mathrm{SVC}$, ratio of tidal volume and slow vital capacity; slope $\mathrm{VE} / \mathrm{VCO}_{2}$, ratio of slope of ventilation and $\mathrm{CO}_{2}$ production; $\mathrm{O}_{2}$ pulse, oxygen pulse; peak $\mathrm{VO}_{2}$, peak oxygen consumption.

\section{Results}

Differences among the groups in pulmonary function and in diaphragm position

Significant differences in several physiological variables among the tested groups were found in the CPET (Table 2). There was a statistically significant difference in total lung capacity (TLC) and in the degree of lung hyperinflation, as expressed by the ratio of residual volume to total lung capacity (RV/TLC) among the 3 groups $(p=0.001)$ (Fig. $2 \mathrm{~A})$. Changes in lung volume were accompanied by corresponding differences in muscle function, namely the respiratory drive $\left(\mathrm{P}_{0.1}\right)$ $(\mathrm{p}=0.048)($ Fig. $2 \mathrm{~B})$ and neuromuscular coupling $\left(\mathrm{P}_{0.1} / \mathrm{V}_{\mathrm{T}}\right)$ 
$(\mathrm{p}=0.047) \quad$ (Fig. 2C). There were also significant differences in operational lung volumes during incremental exercise among the three groups in $\mathrm{V}_{\mathrm{T}} / \mathrm{SVC}$ ratio at maximal exercise $(p=0.0001)$ (Fig. 2D). The maximal height of the diaphragm dome during maximal expiration (DPex) was significantly lower in patients with
COPD. According Dunn's Multiple Comparison test there were statistical significant differences between COPD and control group $(p=0.0016)$, no statistical significant differences between control group and asthma group ( $>0.05)$ and between asthma and COPD group (p>0.05) (Fig. 2E).
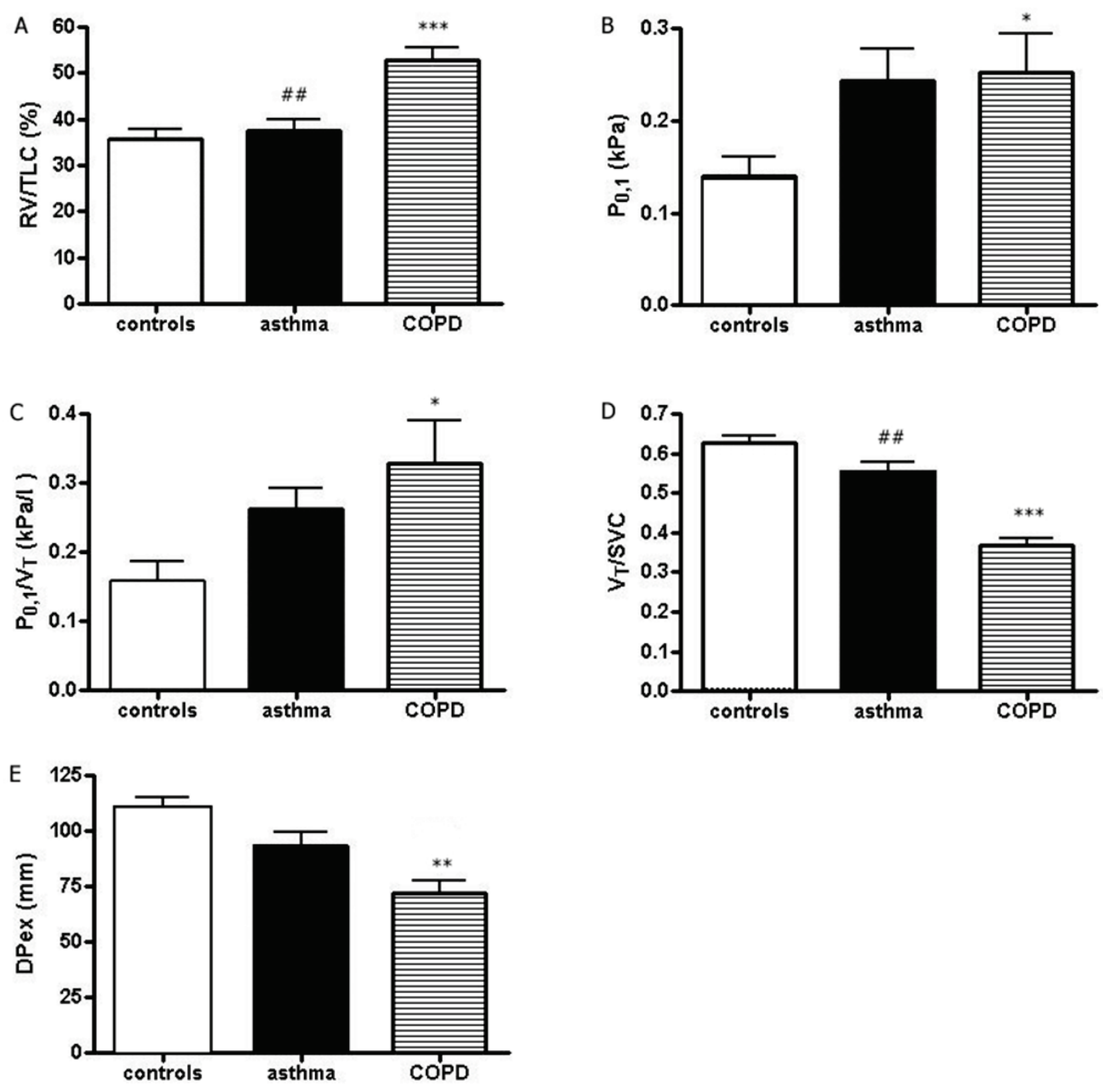

Fig. 2. Differences among 3 groups in $R V / T L C$ (\%) (A), $P_{0.1}(\mathbf{B}), P_{0.1} / V_{T}(k P a / l)\left(\right.$ C), $V_{T} / S V C$ (D), DPex (E). Comparison among 3 groups according Dunn's multiple comparison test. Symbol $*$, **, *** comparison between COPD and control group $(p<0.05, p<0.01$, $\mathrm{p} \leq 0.001)$; \#\# comparison between COPD and asthma group $(\mathrm{p}<0.01)$; no statistical differences between asthma group and control group in any parametrs. 

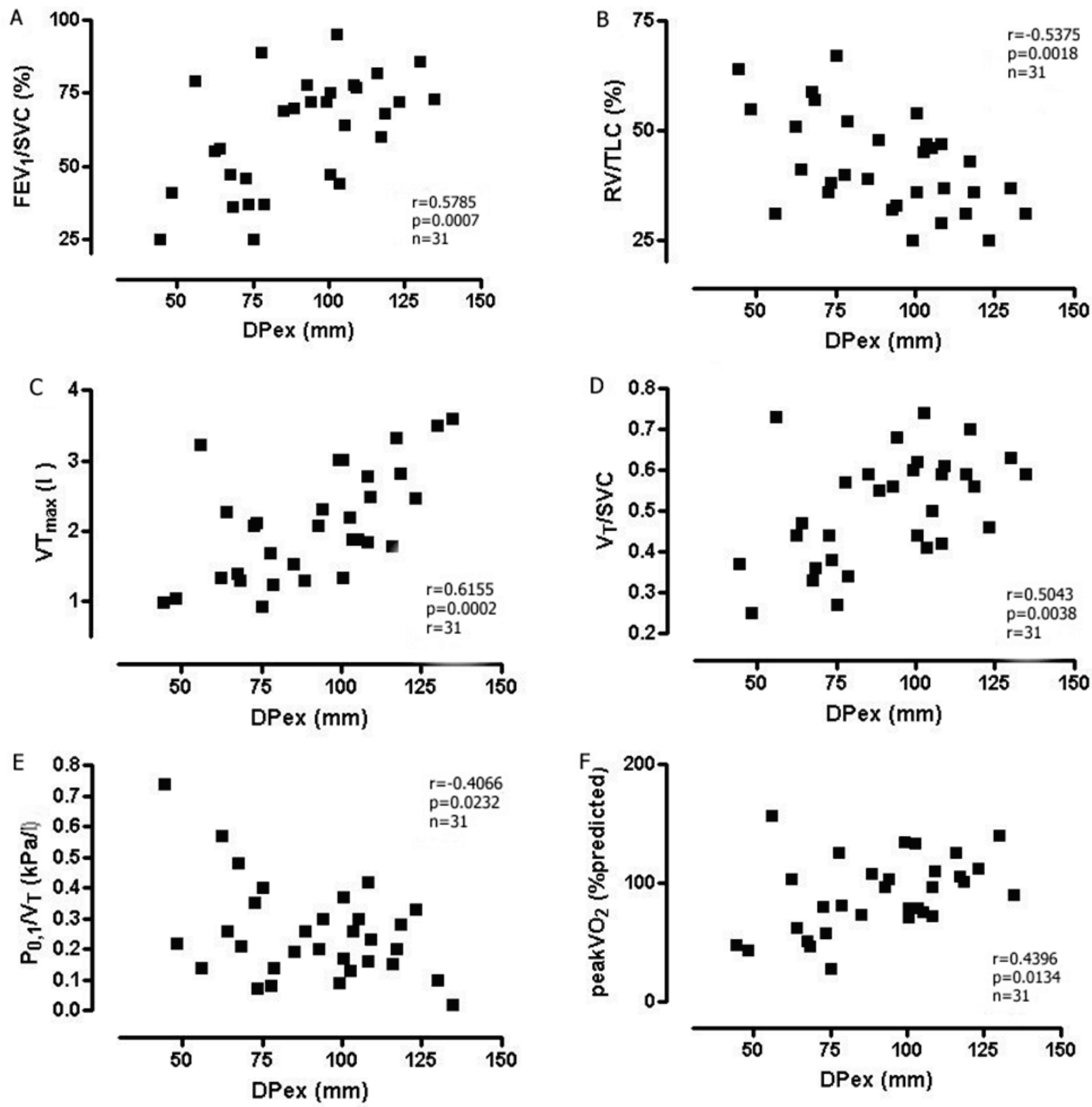

Fig. 3. Relationship between DPex and the ratio of forced expiratory volume in $1 \mathrm{~s}$ to slow vital capacity FEV $1 / \operatorname{SVC}(\mathbf{A})$, DPex and the ratio of the residual volume to total lung capacity $(\mathrm{RV} / \mathrm{TLC})(\mathbf{B})$, maximal tidal volume $\left(\mathrm{V}_{\mathrm{Tmax}}\right)[\mathrm{I}]$ and $\mathrm{DPex}(\mathbf{C}), \mathrm{V}_{\mathrm{T}} / \mathrm{SVC}$ and DPex (D), $\mathrm{P}_{0.1} / \mathrm{V}_{\mathrm{T}}$ and DPex $(\mathbf{E})$, peak $\mathrm{VO}_{2}$ during incremental exercise is positively correlated with DPex $(\mathbf{F})$.

The relationship between pulmonary function and diaphragm position

A rest and exercise test showed that DPex has a significant correlation with several pulmonary function tests. Our results show that the lung volumes determine the position of the diaphragm and the function of the respiratory muscles, mainly in full expiration. For example, significant correlations were found for DPex and the ratio of forced expiratory volume in $1 \mathrm{~s}$ to slow vital capacity the ratio of forced expiratory volume in $1 \mathrm{~s}$ to slow vital capacity $\mathrm{FEV}_{1} / \mathrm{SVC} \quad(\%, \mathrm{r}=0.5785$, $\mathrm{p}=0.0007$ ) (Fig. 3A) and for DPex and the ratio of the residual volume to total lung capacity (RV/TLC) (\%, $\mathrm{r}=-0.5375, \quad \mathrm{p}=0.0018) \quad$ (Fig. 3B). A significant correlation was also found between maximal tidal volume $\left(\mathrm{V}_{\mathrm{Tmax}}\right)$ [1] and DPex ( $\left.\mathrm{r}=0.6155, \mathrm{p}=0.0002\right)$ (Fig. 3C) and between $\mathrm{V}_{\mathrm{T}} / \mathrm{SVC}$ and DPex $(\mathrm{r}=0.5043, \mathrm{p}=0.0038)$ (Fig. 3D). Many tests of respiratory muscle function were related to the DPex, e.g. $\mathrm{P}_{0.1} / \mathrm{V}_{\mathrm{T}}(\mathrm{r}=-0.4066, \mathrm{p}=0.0232)$ (Fig. 3E). We also found the relationship between operational volume during CPET and DPex namely, $\mathrm{V}_{\text {Tmax }}[1]$ and DPex $(\mathrm{r}=0.6155, \mathrm{p}=0.0002)$, and the 
relationship between diaphragm position and cardiac function, as assessed by the oxygen pulse (at peak $\mathrm{VO}_{2}$ ) during CPET. Peak $\mathrm{VO}_{2}$ during incremental exercise is positively correlated with DPex $(\mathrm{r}=0.4396, \mathrm{p}=0.0134)$ (Fig. 3F).

No significant relationships were found between inclination of the diaphragm, either in inspiration or in expiration, and pulmonary function tests.

\section{Discussion}

In the present study, we have shown that lung hyperinflation has a major impact on the shape and position of the diaphragm, confirming previous findings (De Troyer and Wilson 2009, Plathow et al. 2004). We have also shown that the shape and position of the diaphragm correlates not only with lung volumes, but also with the strength of the respiratory muscles, operational lung volumes during CPET, and exercise tolerance.

\section{Differences among groups}

Not surprisingly, we found larger lung volumes in the COPD patients than in the healthy subjects. This is a known fact that has been demonstrated in a number of previous studies. Patients with asthma have a pulmonary function comparable to that of healthy subjects. The aim of our study was to investigate the pulmonary functions of COPD patients and asthma patients, and we therefore included asthma patients with normal pulmonary functions with an $\mathrm{FEV}_{1} / \mathrm{SVC}$ ratio higher than the lower limit of normal.

Although the asthma patients had similar pulmonary functions to those of the healthy subjects, their DPex was lower in our experiment. However, it was not as low as in the COPD patients. We can therefore assume that the shape of the diaphragm is not only influenced by the size of the pulmonary volumes, but that it is also influenced by other factors, such as age, gender and body mass index (Suwatanapongched et al. 2003).

The presence of obesity in COPD effects the respiratory mechanics and muscle function (O'Donnell et al. 2014). There is reduced efficacy of the diaphragm in obese due to an increased abdominal pressure and reduced abdominal compliance. Obesity reduces the caudal excursion of the diaphragm and therefore reduces alveolar ventilation (Steier et al. 2009). The diaphragm may be overstretched in patients with abdominal obesity, thereby placing it at a mechanical disadvantage, which may contribute to dyspnea (Ferretti et al. 2001). We could not study the effect of obesity on pulmonary function and respiratory muscle function in this group, because BMI was virtually normal and had low variability in our COPD patients.

Although we had expected differences in other diaphragm parameters (e.g. inclination and shape during maximal inspiration), no significant differences were observed. We can assume that the major problem in patients with airflow limitation is to empty the lungs. This also correlates with the findings of diaphragm MRI, where the most detectable differences are in DPex. Our aim was to compare the height of the dome of DPex, where we expected the restrictions due to the inability to empty the lungs and therefore the differences between the groups. The disease itself changes the size of the lungs and chest. Diaphragm height in maximal inspiration will be similarly affected by the disease (but substantially less) as DPex. Although pulmonary function has long been reported in patients with pulmonary obstruction, it is difficult to measure and describe the respiratory motions because of the limited methods available for real time dynamic assessment. In some studies, chest radiographs were used to assess diaphragm shape and position (Suwatanapongched et al. 2003). MRI is currently considered to be a useful technique for making dynamical and noninvasive assessments of the respiratory mechanisms of the diaphragm (Plathow et al. 2004, Suga et al. 1999, Iochum et al. 2002, Cluzel et al. 2000).

The exact mechanism of the motion and shape of the diaphragm is not completely understood. In airflow limitation, the greater end-expiratory lung volume plays a dominant role in increasing the work of breathing in patients. The increased airway resistance and dynamic lung hyperinflation, which are characteristic of COPD, make the respiratory muscles work chronically against an increased load (Similowski et al. 1991). There were small differences between 3 groups in the inclination of the diaphragm in expiration, but the differences do not reach statistical significance.

These findings confirm our initial hypothesis that the diaphragmatic position in patients with pulmonary obstruction would be different from the diaphragmatic position in subjects with normal pulmonary function. The results suggest what previous studies have shown. Patients with COPD typically have irreversible progressive airway obstruction (Pauwels et al. 2001). This is evident both in the measurements at rest (static lung volumes) and in the measurements during the 
CPET (operational volumes), in which dynamic hyperinflation is a major determinant of exercise tolerance.

An unexpected finding was that the respiratory muscle functions for asthma patients were comparable with the respiratory muscle functions for COPD patients. The respiratory drive $\mathrm{P}_{0.1}$ was significantly lower in the asthma patients than in the healthy subjects, and it was practically the same as in COPD patients. Similarly, asthma patients tend to have neuromuscular coupling $\left(\mathrm{P}_{0.1} / \mathrm{V}_{\mathrm{T}}\right)$ that approaches the values proven in patients with COPD. There are no statistical significant differences between the groups in $\mathrm{T}_{\mathrm{TMUS}}$ and maximal expiratory pressures at the mouth $\left(\mathrm{PE}_{\max }\right)$. Suprisingly, patients with asthma tend to have lower $\mathrm{PE}_{\max }$ and higher $\mathrm{T}_{\mathrm{TMUS}}$ than COPD patients and healthy subjects.

The absence of differences in $\mathrm{PE}_{\max }$ and $\mathrm{PI}_{\max }$ is probably due to the longstanding increase in the workload of the respiratory muscles in patients with COPD (Polkey 2002). In other words, the respiratory muscles of COPD patients seem to be trained to deal with this kind of workload. However, asthmatic breathing efficiency may be influenced by episodic bronchoconstriction. Nevertheless, the patients enrolled in our study had good long-term control of the disease. It is therefore likely that the function of the respiratory muscles of asthma patients was more affected by a low level of physical activity than by lung function alone.

Some studies have reported that the inspiratory muscles are weaker in patients with asthma than in healthy individuals (Allen et al. 1993, De Bruin et al. 1997), while others have observed no strength deficit (Lavietes et al. 1988, Stell et al. 2001). However, there is some evidence of an inability to achieve full neural activation of the diaphragm during voluntary efforts (Allen et al. 1993), which may be due to impaired reflex excitation of the inspiratory motoneurons (Butler et al. 1996). A non-invasive index of global inspiratory muscle activity ( $\mathrm{T}_{\text {TMUS }}$ ) has been used in a recent study. In most cases, simple non-invasive tests are sufficient to confirm or to eliminate significant respiratory muscle weakness (Fitting 2012). A partial explanation may be provided by differences in operational lung volumes $\left(\mathrm{V}_{\mathrm{T}}, \mathrm{V}_{\mathrm{T}} / \mathrm{SVC}\right.$, $\mathrm{V}_{\mathrm{T}} / \mathrm{IC}$ ), which were lowest in patients with COPD. Measuring the operational volumes during physical activity is helpful in quantifying changes in the end of expiration, reflecting the rises in the residual volume (RV). This is referred to as dynamic hyperinflation. This phenomenon appears due to a decrease in the elastic recoil of the lung, which is a typical phenomenon in patients with COPD (Papandrinopoulou et al. 2012).

An interesting finding was that asthma patients showed dynamic hyperinflation during an exercise test similar to that of patients with COPD. It can therefore be assumed that long-standing asthma is accompanied by a decrease in the elastic recoil of the lung, though to a lesser degree than is seen in COPD (Wassermann 2002). This study showed that patients with severe asthma have a change in the elasticity of their lung tissue. However, it is not clear whether dynamic hyperinflation is the only determinant of exercise tolerance. Another determinant is likely to be a decline in fitness (Lucas and Platts-Mills 2005, Rasmussen et al. 2000).

The relationship between pulmonary function, respiratory muscle strength and diaphragm position

We also compared the MRI results with pulmonary functions, respiratory muscle function and exercise tolerance within each group. We were interested to find whether there is a clear relationship between varying degrees of impairment of pulmonary function and the shape of the diaphragm. In other words, we were looking for the dependence between anatomic changes of the respiratory system, on the one hand, and respiratory muscle function and exercise tolerance, on the other.

The first finding is that the height of the diaphragm has an inverse relationship with the age of individuals, irrespective of whether they are ill.

As expected, we have shown that DPex decreases with increasing volumes and with airway resistance. It can be assumed that the greater the pulmonary hyperinflation, the lung overdistension and the flow limitation are, the lower DPex will be (Cassart et al. 1997, McKenzie et al. 1994). Along with the lower position of the diaphragm, there is evident influence on the size of the chest. The AP size of the diaphragm increases with pulmonary hyperinflation. This forms the basis of the classic physical examination findings of a barrel chest in patients with COPD (Moua and Wood 2008).

Parallel with the decrease in DPex, there is a noticeable increase in $\mathrm{P}_{0.1}$ and $\mathrm{P}_{0.1} / \mathrm{V}_{\mathrm{T}}$. It is therefore clearly evident that respiratory muscle function is dependent on increasing lung volumes. This relationship suggests that the diaphragmatic movement does not contribute sufficiently to the change in lung volume during exercise. In patients with lung obstruction, the expiratory flow limitation prolongs expiration, and this 
may also lead to pulmonary hyperinflation (Dal Vecchio et al. 1990). The relationship between hyperinflation and peak $\mathrm{VO}_{2}$ in patients with severe chronic obstructive pulmonary disease was presented in previous study (Vassaux et al. 2008). We have also found a relationship between the operational volumes during CPET and diaphragm position that is consistent with other studies (Eichinger et al. 2007). The decrease of $\mathrm{V}_{\mathrm{T}}$ and $\mathrm{V}_{\mathrm{T}} / \mathrm{SVC}$ indirectly indicates the magnitude of dynamic hyperinflation. The relation $\mathrm{V}_{\mathrm{T}}$ /DPex means that the higher $\mathrm{V}_{\mathrm{T}}$ is, the higher is dome of the diaphragm during maximal expiration, which means that there is no or little hyperinflation and vice versa.

The positive correlation of $\mathrm{FEV}_{1} / \mathrm{SVC} \%$ and DPex means that with decreasing airway resistance decreases the position of diaphragm during maximal expiration. Sometimes, hyperinflation is inferred from an increase in the ratio of RV to TLC, a feature otherwise known as air-trapping. Negative correlation between RV/TLC a DPex means that the more hyperinflation is, the lower is dome of diaphragm during maximal expiration.

Another correlation was found between cardiac function as assessed by the oxygen pulse (peak $\mathrm{VO}_{2}$ ) during CPET and diaphragm position. Peak $\mathrm{VO}_{2}$ during incremental exercise correlates positively with DPex. Peak $\mathrm{VO}_{2}$ reflects the aerobic physical fitness of the individual, and is an important determinant of her/his endurance capacity during prolonged, sub-maximal exercise.

In this study, we have reviewed some physiological concepts that relate to the diaphragm in patients with obstructive pulmonary diseases.

However, there are weaknesses in the design of our study, namely in the assessment of the respiratory muscle function. Maximal inspiratory and expiratory pressures are commonly used to measure the maximal strength of muscles. These tests are volitional, and the results depend on the willingness and cooperativeness of the subject. Although mouth occlusion tests are proved and widely accepted, it is usually recommended to use multiple tests, such as nasal sniff tests, for the assessment. A tension-time index of the inspiratory muscles $\left(\mathrm{T}_{\mathrm{TI}}\right)$, based on oesophageal pressure measurements, is used to assess the overall activity of the inspiratory muscles and the inspiratory muscle effort.
Measurements of this kind are invasive, as they require the insertion of an oesophageal balloon (Chlumský et al. 2006). Since our patients were not able or willing to undergo these invasive measurements, instead $\mathrm{T}_{\mathrm{TMUS}}$ was used.

The interpretation of the pulmonary function test requires an appreciation of normal values. There are no normal values available for chest size, and we did not even correlate chest size with anthropometric parameters. Nevertheless, it is obvious than chest size influences the shape and the position of the diaphragm (Suwatanapongched et al. 2003).

The gender representation in the groups in our study differed, and the results of our study were derived from a small number of patients. Comparative studies in a larger number of patients and gender- and age-matched controls are therefore necessary.

\section{Conclusion}

MRI is seems to be a promising investigative tool for clinical analysis of diaphragm motion in patients with lung disease. The application of MRI can explain how the airflow limitation affects the position of the diaphragm, which has a great impact on respiratory muscle function.

There is an apparent relationship between the position of the diaphragm and the pulmonary functions and exercise tolerance. Abnormalities can be present even in mild forms of airflow limitation, such as asthma. A better understanding of the mechanism and the assessment of the pathology of airflow limitation may lead to better therapy for obstructive pulmonary disease.

\section{Conflict of Interest}

There is no conflict of interest.

\section{Acknowledgements}

This work was supported by the project UK P38 and Internal Grant Agency of the Ministry of Education, Youth and Sports of the Czech Republic (MSM 21620864) and by the Grant Agency of Czech Republic (GAČR 407/12/0166), the data analyses were partially supported by the Grant Agency of the Czech Technical University in Prague No. SGS13/203/OHK3/3T/13. 


\section{References}

ALLEN GM, MCKENZIE DK, GANDEVIA SC, BASS S: Reduced voluntary drive to breathe in asthmatic subjects. Respir Physiol 93: 29-40, 1993.

AMERICAN THORACIC SOCIETY/EUROPEAN RESPIRATORY SOCIETY: ATS/ERS Statement on respiratory muscle testing. Am J Respir Crit Care Med 166: 518-624, 2002.

BARNES PJ: Immunology of asthma and chronic obstructive pulmonary disease. Nat Rev Immunol 8: 183-192, 2008.

BLACK LF, HYATT RE: Maximal respiratory pressures: normal values and relationship to age and sex. Am Rev Respir Dis 99: 696-702, 1969.

BUTLER JE, MCKENZIE DK, GANDEVIA SC: Impaired reflex responses to airway occlusion in the inspiratory muscles of asthmatic subjects. Thorax 51: 490-495, 1996.

CASSART M, PETTIAUX N, GEVENOIS PA, PAIVA M, ESTENNE M: Effect of chronic hyperinflation on diaphragm length and surface area. Am J Respir Crit Care Med 156: 504-508, 1997.

CHLUMSKÝ J, FILIPOVA P, TERL M: Non-invasive assessment of respiratory muscle function and its relationship to exercise tolerance in patients with chronic obstructive pulmonary disease. J Int Med Res 34: 240-246, 2006.

CLOZEL P, SIMILOWSKI T, CHARTRAND-LEFEBVRE C, ZELTER M, DERENNE JP, GREINIER PA: Diaphragm and chest wall: assessment of the inspiratory pump with MR imaging-preliminary observations. Radiology 215: 574-583, 2000.

DAL VECCHIO L, POLESE G, POGGI R, ROSSI A: "Intrinsic" positive end-expiratory pressure in stable patients with chronic obstructive pulmonary disease. Eur Respir J 3: 74-80, 1990.

DE BRUIN PF, UEKI J, WATSON A, PRIDE NB: Size and strength of the respiratory and quadriceps muscles in patients with chronic asthma. Eur Respir J 10: 59-64, 1997.

DE TROYER A, WILSON TA: Effect of acute inflation on the mechanics of the inspiratory muscles. $J$ Appl Physiol 107: 315-323, 2009.

EICHINGER M, PUDERBACH M, SMITH H-J, TETZLAFF R, KOPP-SCHNEIDER A, BOCK M, BIEDERER J, KAUCZOR H-U: Magnetic resonance-compatible-spirometry: principle, technical evaluation and application. Eur Respir J 30: 972-979, 2007.

FERRETTI A, GIAMPICCOLO P, CAVALLI A, MILIC-EMILI J, TANTUCCI C: Expiratory flow limitation and orthopnea in massively obese subjects. Chest 119: 1401-1408, 2001.

FITTING JW: Volitional assessment of respiratory muscle strength. Monaldi Arch Chest Dis 77: 19-22, 2012.

IOCHUM S, WALTER F, SEBBAG H, GROSDIDIER G, BLUM AG: Imaging of diaphragmatic injury: a diagnostic challenge? Radiographics 22: 103-118, 2002.

LARSON JL, COVEY MK, CORBRIDGE S: Inspiratory muscle strength in chronic obstructive pulmonary disease. AACN Clin Issues 13: 320-332, 2002.

LAVIETES MH, GROCELA JA, MANIATIS T, POTULSKI F, RITTER AB, SUNDERAM G: Inspiratory muscle strength in asthma. Chest 93: 1043-1048, 1988.

LUCAS SR, PLATTS-MILLS TA: Physical activity and exercise in asthma: relevance to etiology and treatment. J Allergy Clin Immunol 115: 928-934, 2005.

MCKENZIE DK, GANDEVIA SC, GORMAN RB, SOUTHON FC: Dynamic changes in the zone of apposition and diaphragm length during maximal respiratory efforts. Thorax 49: 634-638, 1994.

MOUA T, WOOD K: COPD and PE: a clinical dilemma. Int J Chron Obstruct Pulmon Dis 3: 277-284, 2008.

NAKAWAH MO, HAWKINS C, BARBANDI F: Asthma, chronic obstructive pulmonary disease (COPD), and the overlap syndrome. J Am Board Fam Med 26: 470-477, 2013.

O'DONNEL DE, CIAVAGLIA CE, NEDER JA: When obesity and chronic obstructive pulmonary disease collide. Physiological and clinical consequences. Ann Am Thorac Soc 11: 635-644, 2014.

PAPANDRINOPOULOU D, TZOUDA V, TSOUKALAS G: Lung compliance and chronic obstructive pulmonary disease. Pulm Med 2012: 542769, 2012. 
PAUWELS RA, BUIST AS, CALVERLEY PM, JENKINS CR, HURD SS: Global strategy for the diagnosis, management, and prevention of chronic obstructive pulmonary disease. NHLBI/WHO Global Initiative for Chronic Obstructive Lung Disease (GOLD) Workshop summary. Am J Respir Crit Care Med 163: 1256-1276, 2001.

PLATHOW C, FINK C, LEY S, PUDERBACH M, EICHINGER M, SCHMÄHL A, KAUCZOR H-U: Measurement of diaphragmatic length during the breathing cycle by dynamic MRI: comparison between healthy adults and patients with an intrathoracic tumor. Eur Radiol 14: 1392-1399, 2004.

POLKEY MI: Muscle metabolism and exercise tolerance in COPD. Chest 121: 131-135, 2002.

QUANJER P, DALHUIJSEN A, VAN ZORAMEN B: Standardised lung function testing. Report of the working party for the European Community for Coal and Steel. Bull Eur Physiopathol Respir 19: 1-95, 1983.

RASMUSSEN F, LAMBRECHTSEN J, SIERSTED HC, HANSEN HS, HANSEN NC: Low physical fitness in childhood is associated with the development of asthma in young adulthood: the Odense schoolchild study. Eur Respir J 16: 866-870, 2000.

SIMILOWSKI T, YAN S, GAUTHIER AP, MACKLEM PT, BELLEMARE F: Contractile properties of the human diaphragm during chronic hyperinflation. $N$ Engl J Med 325: 917-923, 1991.

STEIER J, JOLLEY CJ, SEYMOUR J, ROUGHTON M, POLKEY MI, MOXHAM J: Neural respiratory drive in obesity. Thorax 64: 719-725, 2009.

STELL IM, POLKEY MI, REES PJ, GREEN M, MOXHAM J: Inspiratory muscle strength in acute asthma. Chest 120: 757-764, 2001.

SUGA K, TSUKUDA T, AWAYA H, TAKANO K, KOIKE S, MATSUNAGA N, SUGI K, ESATO K: Impaired respiratory mechanics in pulmonary emphysema: evaluation with dynamic breathing MRI. J Magn Reson Imaging 10: 510-520, 1999.

SUWATANAPONGCHED T, GIERADA DS, SLONE RM, PILGRAM TK, TUTEUR PG: Variation in diaphragm position and shape in adults with normal pulmonary function. Chest 123: 2019-2027, 2003.

VASSAUX C, TORRE-BOUSCOULET L, ZEINELDINE S, CORTOPASSI F, PAZ-DIAZ H, CELLI BR, PINTOPLATA VM: Effects of hyperinflation on the oxygen pulse as a marker of cardiac performance in COPD. Eur Respir J 32: 1275-1282, 2008.

WASSERMANN K: Is asthma another interstitial lung disease? Chest 121: 673-674, 2002. 